\title{
Strain Mapping and Nanocrystallite Size Determination by Neutron Diffraction in an Aluminum Alloy (AA5083) Severely Plastically Deformed through Equal Channel Angular Pressing
}

\author{
P. A. González Crespo, ${ }^{1}$ C. Luis Pérez, ${ }^{1}$ Darren J. Hughes, ${ }^{2}$ and X. Turrillas ${ }^{3}$ \\ ${ }^{1}$ Departamento de Ingeniería Mecánica, Energética y de Materiales, ETSIIT-UPNA, Campus de Arrosadía S/N, \\ 31006 Pamplona, Spain \\ ${ }^{2}$ WMG, International Manufacturing Centre, University of Warwick, Coventry CV4 7AL, UK \\ ${ }^{3}$ Department of Crystallography, Institute of Materials Science of Barcelona, Spanish Council for Scientific Research, \\ ICMAB-CSIC, UAB Campus, 08193 Bellaterra, Spain
}

Correspondence should be addressed to P. A. González Crespo; pagonzalez@unavarra.es

Received 28 September 2013; Accepted 1 November 2013

Academic Editor: Khaled Youssef

Copyright (C) 2013 P. A. González Crespo et al. This is an open access article distributed under the Creative Commons Attribution License, which permits unrestricted use, distribution, and reproduction in any medium, provided the original work is properly cited.

Six specimens of an aluminum alloy (AA-5083) extruded by Equal Channel Angular Pressing following two different routes plus a blank sample were examined with a neutron radiation of $1.5448 \AA$. Macrostrain maps from the (311) reflection were obtained. A clear difference about accumulated macrostrain with the extrusion cycles between the two routes is shown. The diffraction data of annealed specimens did permit to estimate crystallite sizes that range between $89 \mathrm{~nm}$ and $115 \mathrm{~nm}$ depending on the routes.

\section{Introduction}

"Equal Channel Angular Pressing" (ECAP) is a powerful method to produce nanostructured materials in bulk samples [1] — with the resulting enhancement of its mechanical properties-through a severe plastic deformation (SPD) by simple shear, without significant alterations in the original shape. One of the advantages of this mechanical treatment is its scalability to produce large pieces at industrial scale with enhanced mechanical properties [2].

Residual stresses remain in a polycrystalline material in a severe plastically deformed state-after all external forces are removed-as long as inelastic deformation is involved since interaction between grains constraints free deformation. Those induced residual stresses could be very detrimental to the performance of the material and could shorten fatigue lifetimes [3]. The first step to calculate stresses in a material is to evaluate macrostrain-using X-rays or neutron-by measuring the diffraction peaks shifts [4]. A more elaborate treatment of peak shapes allows, in principle, to estimate both lattice or microstrain $\left(\Gamma_{s}\right)$ and crystallite size $\left(\Gamma_{t}\right)$ of the samples. An interesting work in dealing with these issues is due to Mittemeijer and Welzel [5].

Since both residual strain and crystallite size (also referred to as dislocation cell size) broaden the diffraction peaks, a strategy to isolate them is to recover the deformed specimens by a moderate thermal treatment, and a further diffraction scanning would show the peak broadening only due to crystallite size. Both are very important microstructural issues in ECAP processes [6], especially if we consider that ECAP is a mechanical treatment of materials that potentially allow us to obtain ultrafine grain microstructures. Concerning the crystallite size in plastically deformed materials, that size could fit with dislocation cells rather than grains or subgrains (only if recovered could have a good agreement between both). Thus X-ray and neutron diffraction are complementary experimental techniques with electron microscopy (such as TEM or EBSD) to discriminate between true grain sizes and crystalline domains. On the other hand these experimental findings are important for the validation of modelling obtained by, for example, finite elements methods (FEM) [7]. 
In the next sections a neutron diffraction study that includes strain maps of aluminium alloy specimens-treated by ECAP-is presented. Here it is worth to mention the work of Ortiz and Shaw [8]. They presented an X-ray diffraction study on aluminum alloys, also severely deformed, but by other techniques. Although earlier works [9] have shown textures evolution of aluminium alloys by neutron scattering, this is the first time that neutron diffraction experimental results on ECAP-processed specimens are discussed.

\section{Preparation of Specimens}

The specimens of as-cast comercial aluminium alloy AA5083 (93.69\% Al; 4.67\% Mg; 0.70\% Mn; 0.15\% Cr) were machined to parallepipedic billets of $9 \times 9 \times 70 \mathrm{~mm}$. The extrusions were carried out in our $400 \mathrm{kN}$ ECAE press at a strain rate of $50 \mathrm{~mm} / \mathrm{s}$ at room temperature using PTFE spray and $\mathrm{MoS}_{2}$ as lubricants. The billets were extruded through an equal channel die of $90^{\circ}$ up to 4 passes. A theoretical plastic strain of $\epsilon=1.15$ per pass was estimated according to the models described in [10]. The billets were processed through two different routes: route $\mathrm{A}$ with constant path between successive passes and route $C$, where the sample is being rotated by $180^{\circ}$ after each pass, following the procedure described in [11]. We had thus a total of 7 specimens to be examined by neutron scattering: a blank or control specimen as cast ("strain-free"), two of two passes called 2A and $2 \mathrm{C}$, another two called $3 \mathrm{~A}$ and $3 \mathrm{C}$, and finally two called $4 \mathrm{~A}$ and $4 \mathrm{C}$. The mechanical properties of specimens were characterized prior to the neutron analysis [12]. Finally, after neutron diffraction of the all seven specimens, the $4 \mathrm{~A}$ and $4 \mathrm{C}$ samples were annealed at $220^{\circ} \mathrm{C}$ during one and a half hour in order to relieve stresses. These recovered specimens were analyzed again by neutron diffraction.

\section{Neutron Diffraction}

Neutron diffraction experiments were carried out on the strain imager SALSA (Strain Analyser for Large-Scale Engineering Applications) at ILL, Grenoble, France. More details about this facility can be found in $[13,14]$. The neutron wavelength selected to probe the eight specimens was set to $1.5448 \AA$. The collimating and receiving slits were set to get a volume gauge of $1 \times 1 \times 50 \mathrm{~mm}^{3}$. In Figure 1(a) the arrangements for the data acquisition can be seen with samples in place among the detector system forming an angle of $78.8^{\circ}$ with the incoming beam. This angle corresponds to the (311) reflection. The $2 \Theta$ region between $77^{\circ}$ and $81^{\circ}$ was scanned by steps of $0.025^{\circ}$.

A total of 32 points were measured-the gauge being centred in the middle height of the specimens-for every specimen. The positions measured can be seen, marked with crosses, in Figure 1(c). Every volume was measured for 15 minutes.

\section{Data Processing}

Once the data were integrated and corrected with the help of LAMP [15], they were conditioned with scripts written in IDL
[16] to be read by Materials Studio 4.3 [17]. Its Reflex module was used to carry out a Pawley [18] refinement. The contour maps showing the variations of strain were calculated with the subroutines of Transform [19].

\section{Results and Discussion}

With this particular setup parallelepiped volumes along the extrusion axis were scanned. Therefore only the strain of crystallites exhibiting (311) planes parallel to the extrusion axis was measured. The peak shapes of (311) reflection were fitted to a Thompson-Cox-Hastings (TCH) [20] model without asymmetry corrections. The fitting statistics indicators (in $\%)$ were good, ranging from 6 to 8 for $R_{w p}$ and from 4.3 to 5.5 for $R_{p}$. The $d$-spacings and derived cell parameters were determined from the fitted TCH curve. The blank specimen was used to establish the instrumental parameters of peak breadth, assuming that the crystallites size was large enough and that the unprocessed sample was stress-free. Also, its $d$ spacing was determined to be used as $d_{0}$ in order to compute the interplanar distances variations for the rest of specimens.

With these assumptions, the elastic residual strain was estimated after the expression:

$$
e_{i}=\frac{d_{i}-d_{0}}{d_{0}} .
$$

The strain data of the individual elements were computed but also were analysed globally_adding up the diffraction patterns of the 32 elements-to have average values of each individual specimen. A glimpse of the global data can be seen in Table 1, where the cubic cell parameters, rather than the $d$-spacings, are gathered. It has to be stressed that this macrostrain is partial since only in one direction has been measured, just from a set of atomic planes; therefore it gives an incomplete account of the total strain. However it is a good indicator of how the ECAP process affected the samples studied.

The choice of the TCH shape was not casual. This model explicitly takes account of the broadening due to both lattice strain and crystallite size, the Lorentzian contribution being due to crystallite size and the Gaussian one to lattice strain. Indeed, with this approach, the instrumental broadening introduced in the refinements allows the total broadening to be fitted with the contributions of both lattice strain and crystallite size. The peak shape for the Modified ThompsonCox-Hastings model is defined as a convolution of Lorentzian and Gaussian functions according to

$$
F=\eta L\left(H_{K}\right)+(1-\eta) G\left(H_{k}\right)
$$

where the mixing parameter is given by the expression $\eta=$ $1.36603 q-0.47719 q^{2}+0.11116$ and $q=\Gamma_{L} / H_{K}$.

The empirical function that defines the FWHM is

$$
H_{K}=\left(\Gamma_{G}^{5}+A \Gamma_{G}^{4} \Gamma_{L}+B \Gamma_{G}^{3} \Gamma_{L}^{2}+C \Gamma_{G}^{2} \Gamma_{L}^{3}+D \Gamma_{G} \Gamma_{L}^{4}+\Gamma_{L}^{5}\right)^{0.2}
$$

and $A=2.69269, B=2.42843, C=4.47163$, and $D=$ 0.07842 . 


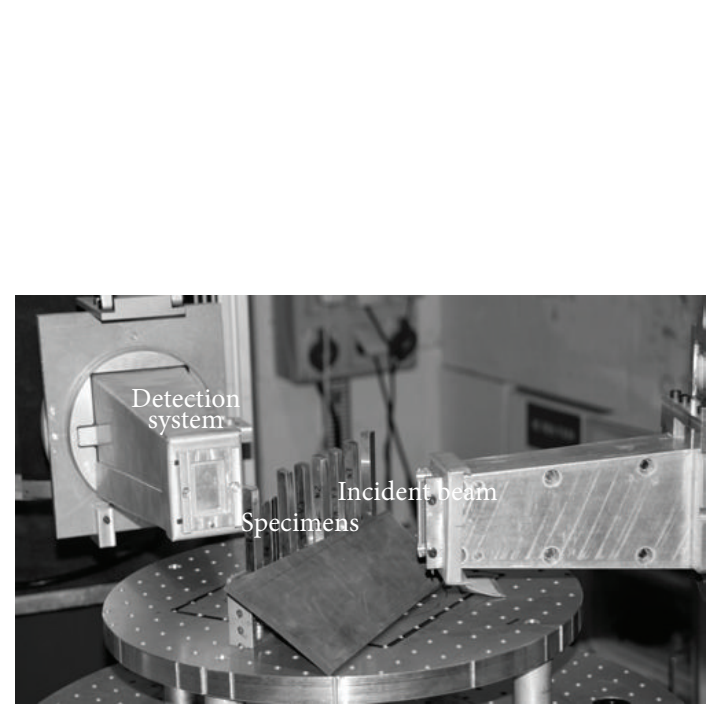

(a)

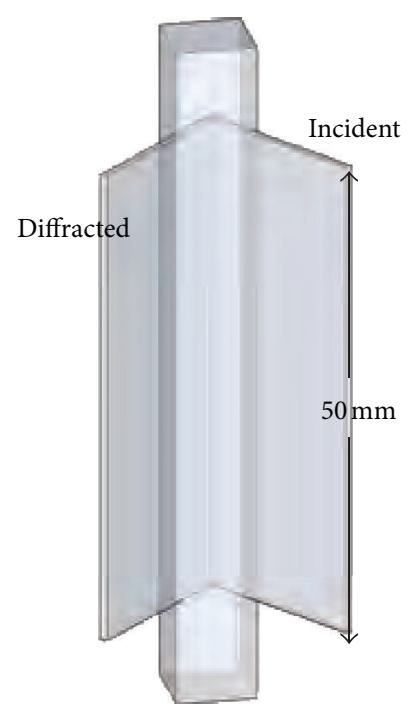

(b)

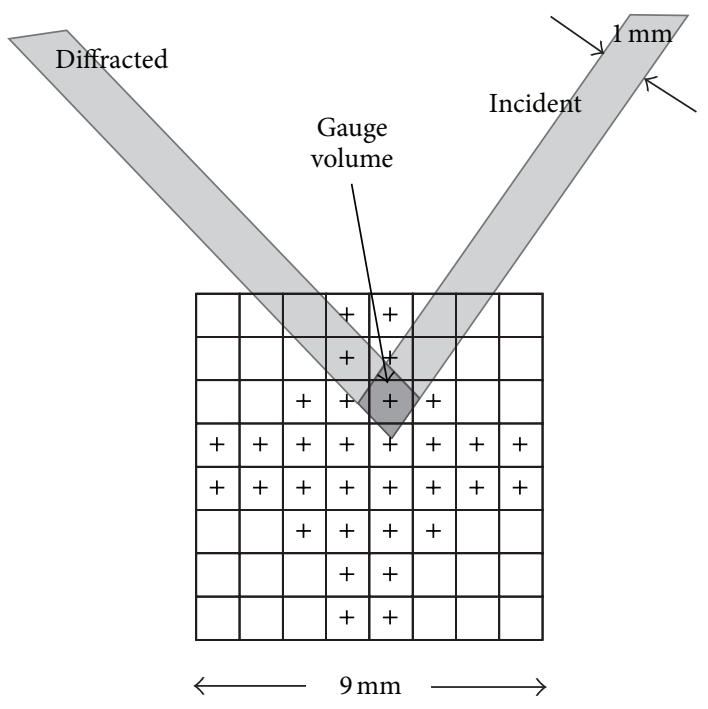

(c)

FIGURE 1: Schematics of the scanning measurements. (a) Photograph of the setup with the specimen in place. (b) Perspective diagram showing the geometry of the sample with incident and diffracted beams delimiting the diffracting or gauge volume. (c) The same diagram as seen from above (in a cross-section to the extrusion axis).

TABLE 1: Average values of cell parameters, macrostrain $\left(e_{i}\right)$, lattice strains (1.s.), and crystallite sizes corresponding to reflection (311). The crystallite size of blank specimen, from SEM micrographs, can be estimated to be around $200 \mathrm{~nm}$.

\begin{tabular}{lcccc}
\hline & $a( \pm 0.0001)$ & $e_{i} \times 10^{4}$ & $1 . s .\left(\Gamma_{s}\right)$ & Xtal size $(\mathrm{nm})$ \\
\hline Blank & 4.0344 & - & - & - \\
$2 \mathrm{~A}$ & 4.0339 & -1.2 & - & - \\
$2 \mathrm{C}$ & 4.0334 & -2.5 & - & - \\
$3 \mathrm{~A}$ & 4.0334 & -2.5 & - & - \\
3C & 4.0333 & -2.7 & 0.24 & - \\
$4 \mathrm{~A}$ & 4.0331 & -3.2 & 0.25 & - \\
$4 \mathrm{C}$ & 4.0333 & -2.7 & - & 89 \\
$4 \mathrm{~A}$ ann. & 4.0337 & -1.7 & - & 115 \\
$4 \mathrm{C}$ ann. & 4.0340 & -1.0 & & - \\
\hline
\end{tabular}



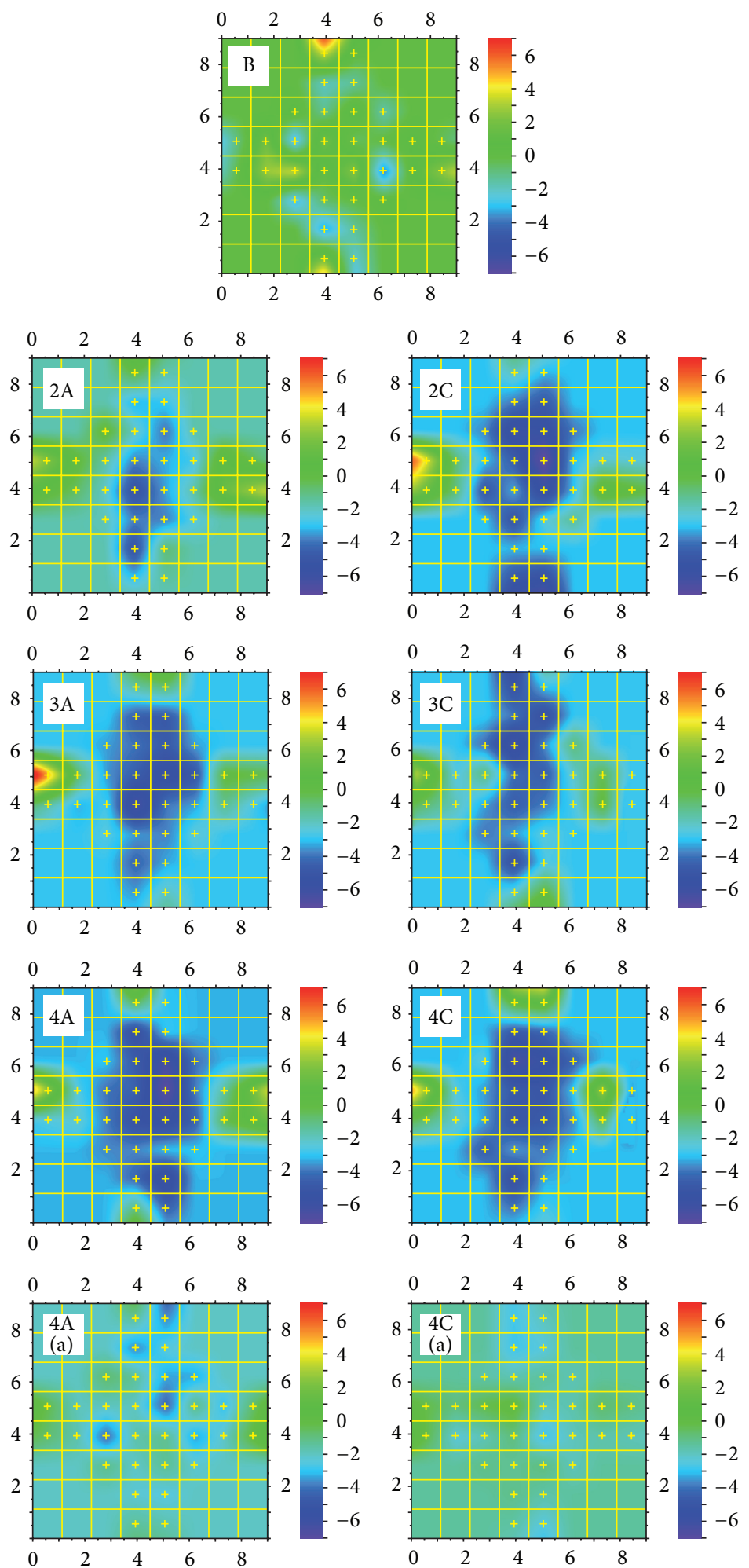

FIGURE 2: Contour colour maps showing macrostrain in the 32 elements measured for all specimens. The values are expressed as $\epsilon_{i} \times 10^{4}$. The dimensions of square sections are in $\mathrm{mm}$. The colour bar on top right indicates the values associated with colours. 

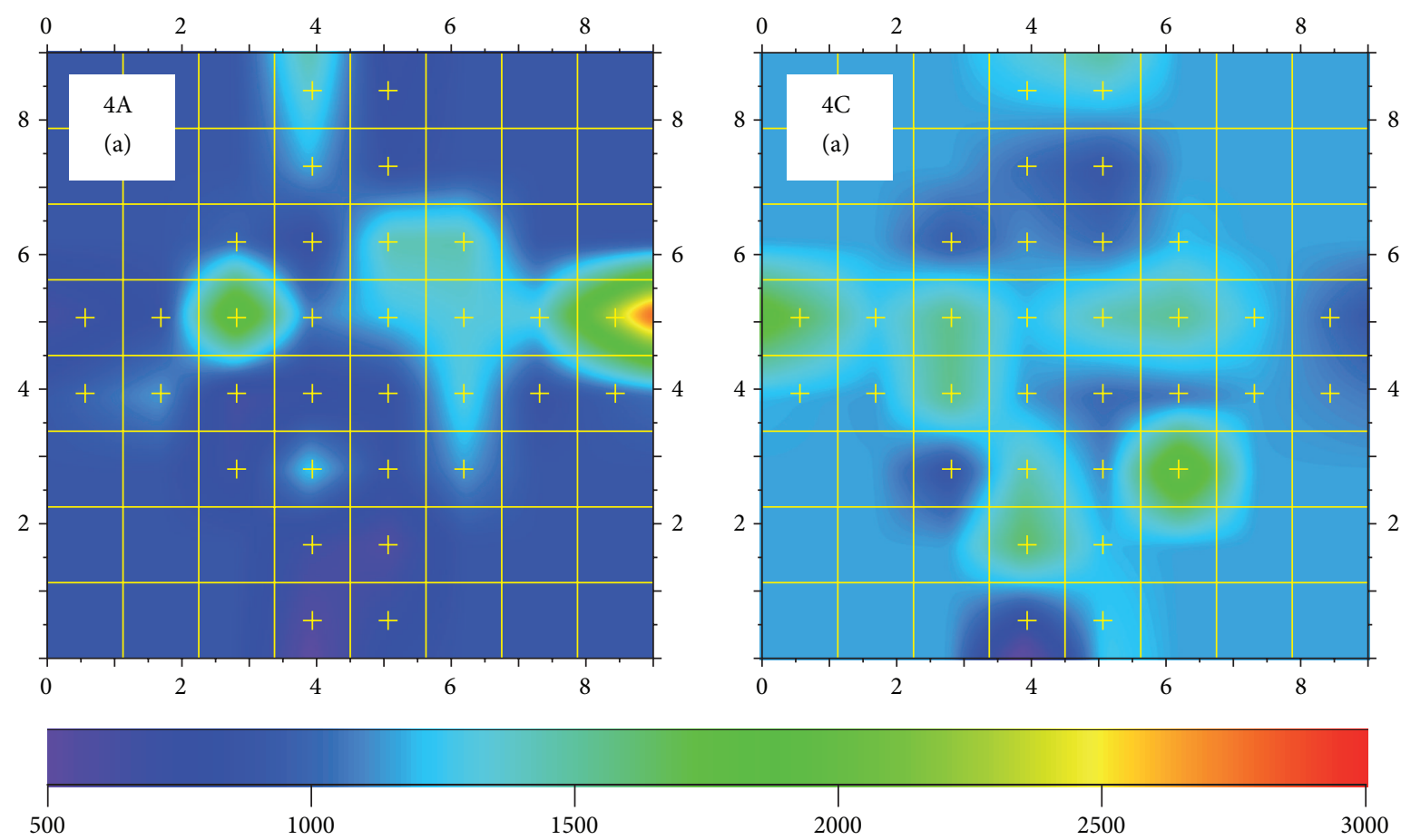

Figure 3: Crystallite sizes (in $\AA$ ) of specimens $4 \mathrm{~A}$ and $4 \mathrm{C}$ after annealing. Dimensions of section in mm. The colour bar scale indicates the values attributed.

Finally the crystallite size $\left(\Gamma_{t}\right)$ and lattice strain $\left(\Gamma_{s}\right)$ broadenings are explicitly introduced in the following expressions:

$$
\begin{gathered}
\Gamma_{G}=\sqrt{U \tan ^{2} \Theta+V \tan \Theta+W+\frac{Z}{\cos ^{2} \Theta} \Gamma_{s}^{2}}, \\
\Gamma_{L}=X \tan \Theta+\frac{Y}{\cos \Theta}+\Gamma_{t},
\end{gathered}
$$

where $U, V, W, X, Y$, and $Z$ are refinable parameters responsible for the instrumental broadening.

In Figure 2, the complete contour maps showing the macrostrain $e_{i}$ of the 32 regions measured for the seven specimens can be seen. The left side of every map represents the internal face treated by the ECAP machine. As a common trend it can be appreciated that the centres of the specimens are compressed. Another common feature is the tendency to expansion (positive macro-strain) in the left and right sides (corresponding to inner and outer faces, resp.). Apparently, there are not noticeable differences among specimens processed through A and C routes. However, the average values gathered in Table 1 are more revealing. The specimens that followed $\mathrm{C}$ route have a practically invariable $e_{i}$ from -2.5 to -2.7 . On the contrary, route A specimens show a steady increase from -1.2 to -3.2 . The fact of turning the specimens in C route seems-on average-to dampen the macro-strain. Even after annealing, the remaining macrostrains show higher values for $4 \mathrm{~A}$ compared to $4 \mathrm{C}$.

In principle, using the Pawley method with $\mathrm{TCH}$ model would allow to measure $\Gamma_{t}$ and $\Gamma_{s}$. However, to deduce or infer from a single experimental peak, both parameters, lattice strain and crystallite size, would be quite risky. To avoid this pitfall, a more conservative approach was followed. Two of the samples already measured, $4 \mathrm{~A}$ and $4 \mathrm{C}$, were annealed at $220^{\circ} \mathrm{C}$ for one and a half hours and then slowly cooled overnight to room temperature in order to release the mechanical tensions and get diffraction data whose strain broadening was minimised; that is, the lattice broadening would not be added to strain broadening. After acquiring data in the same conditions as before, the analyses of the diffraction patterns allowed to estimate the crystallite size neglecting microstrain. The crystallite size obtained for route A was $80 \mathrm{~nm}$ and $130 \mathrm{~nm}$ for route C. These small crystallite size values are consistent with the perception of the ECAP technique as a very effective method of grain refinement by severe plastic deformation. Introducing crystallite sizes in the Pawley refinement analyses of the diffraction data of nonannealed specimens it was possible to estimate the lattice strain broadening contribution to peak broadening. In Table 1 these latest average values corresponding to cell parameters are also included for unprocessed specimens. A map of these size values can be seen in Figure 3.

In Figure 2, the colour contour maps of the annealed samples can be seen. In both cases the strains seem to be more uniformly distributed. Perhaps the annealed 4A sample still exhibits signs of strain in the inner and outer faces; see Figure 2 to compare it. Also the microstrain deduced from Pawley fitting is shown. Again the specimen that suffered from the accumulative cycles of route A seems to exhibit a more irregular pattern, while annealed $4 \mathrm{C}$ is more uniform.

Finally it is worth to mention that these experiments do not shed any light on plastic strain. Only theoretical models, as explained earlier, can estimate it. In this respect it has to 
be said that those models to compute the theoretical plastic strain do not permit to discriminate between $\mathrm{A}$ and $\mathrm{C}$ routes, whereas the experimental neutron diffraction data clearly show the differences in residual elastic strain accumulated by the two routes. Therefore this experimental information is quite valuable and complementary to other experimental results and theoretical estimations.

\section{Conclusions}

Neutron diffraction strain probing in SALSA did permit to estimate elastic residual deformation in specimens of a commercial aluminum alloy (AA-5083) processed by ECAP. It has been shown that irrespective of the route employed either $\mathrm{A}$ or $\mathrm{C}$, the inner part of all the specimens was more compressed than the periphery. The inner and outer faces-in relation to the ECAP machine processing-were less compressed or even slightly expanded, regardless of the route. If an average value of every specimen for the macrostrain is considered, the route $\mathrm{C}$ specimens do not change much with increasing the number of cycles. Contrarily, the specimens treated through A route exhibit a steady increase of macrostrain. Some plastic deformation still remains after annealing and slow cooling in two specimens processed four times by routes A and C, but the sample that followed an A route presented slightly larger values of macrostrain. This agrees with other reports that have demonstrated that this route yields higher deformation and less uniformly distributed. Finally, it has been possible to estimate crystallite sizes on annealed specimens; they ranged from $89 \mathrm{~nm}$ for route A to $115 \mathrm{~nm}$ for route C. This is also in agreement with the higher elastic strain values found for route $A$ and is a reliable indication that smaller grain sizes can be achieved by route $A$.

\section{Acknowledgments}

This work has been possible thanks to financial help of MICINN (Spain) through Project MAT2006-14341-C02-02. Also, ILL has to be acknowledged for the beam time allocation of Experiment no. 1-01-65.

\section{References}

[1] R. Z. Valiev, R. K. Islamgaliev, and I. V. Alexandrov, "Bulk nanostructured materials from severe plastic deformation," Progress in Materials Science, vol. 45, no. 2, pp. 103-189, 2000.

[2] R. Valiev, "Nanostructuring of metals by severe plastic deformation for advanced properties," Nature Materials, vol. 3, no. 8, pp. 511-516, 2004.

[3] P. J. Withers and H. K. D. H. Bhadeshia, "Residual stress part 2-nature and origins," Materials Science and Technology, vol. 17, no. 4, pp. 366-375, 2001.

[4] M. L. Martinez-Perez, F. J. Mompean, J. Ruiz-Hervias et al., "Residual stress profiling in the ferrite and cementite phases of cold-drawn steel rods by synchrotron X-ray and neutron diffraction," Acta Materialia, vol. 52, no. 18, pp. 5303-5313, 2004.

[5] E. J. Mittemeijer and U. Welzel, "The "state of the art" of the diffraction analysis of crystallite size and lattice strain," Zeitschrift fur Kristallographie, vol. 223, no. 9, pp. 552-560, 2008.
[6] F. J. Humphreys, P. B. Prangnell, J. R. Bowen, A. Gholinia, and C. Harris, "Developing stable fine-grain microstructures by large strain deformation," Philosophical Transactions of the Royal Society A, vol. 357, no. 1756, pp. 1663-1681, 1999.

[7] R. Luri, C. J. Luis, and J. Leon, "Finite element modelling and analysis of processing routes by using equal channel angular extrusion," in Proceedings of the 10th International Research/Expert Conference "Trends in the Development of Machinery and Associated Technology" (TMT '06), pp. 773-776, 2006.

[8] A. L. Ortiz and L. Shaw, "X-ray diffraction analysis of a severely plastically deformed aluminum alloy," Acta Materialia, vol. 52, no. 8, pp. 2185-2197, 2004.

[9] T. Liu, Y. D. Wang, S. D. Wu et al., "Textures and mechanical behavior of Mg-3.3\%Li alloy after ECAP," Scripta Materialia, vol. 51, no. 11, pp. 1057-1061, 2004.

[10] K. Oh-Ishi, A. P. Zhilyaev, and T. R. McNelley, "Effect of strain path on evolution of deformation bands during ECAP of pure aluminum," Materials Science and Engineering A, vol. 410-411, pp. 183-187, 2005.

[11] C. J. Luis Pérez, "On the correct selection of the channel die in ECAP processes," Scripta Materialia, vol. 50, no. 3, pp. 387-393, 2004.

[12] C. J. Luis Pérez, P. A. González, and Y. Garcés, "Equal channel angular extrusionin a commercial Al-Mn alloy," Journal of Materials Processing Technology, vol. 143-144, pp. 506-511, 2003.

[13] G. Bruno, T. Pirling, P. J. Withers, W. Hutt, and S. Rowe, "SALSA: strain analyser for large and small scale engineering applications," Journal of Neutron Research, vol. 11, no. 4, pp. 235239, 2003.

[14] T. Pirling, G. Bruno, and P. J. Withers, "SALSA: advances in residual stress measurement at ILL," Materials Science Forum, vol. 524-525, pp. 217-222, 2006.

[15] D. Richard, M. Ferrand, and G. J. Kearley, Large Array Manipulation Program, ILL, 2007.

[16] “IDL v 6. Research Systems Inc.," 2003.

[17] "Materials Studio Modeling v. 4.3 Accelrys Software".

[18] G. S. Pawley, "Unit-cell refinement from powder diffraction scans," Journal of Applied Crystallography, vol. 14, part 14, pp. 357-361, 1981.

[19] “Transform v. 3.4 Fortner Software LLC.," 1998.

[20] P. Thompson, D. E. Cox, and J. B. Hastings, "Rietveld refinement of debye-scherrer synchrotron x-ray data from Al2O3," Journal of Applied Crystallography, vol. 20, part 2, pp. 79-83, 1987. 

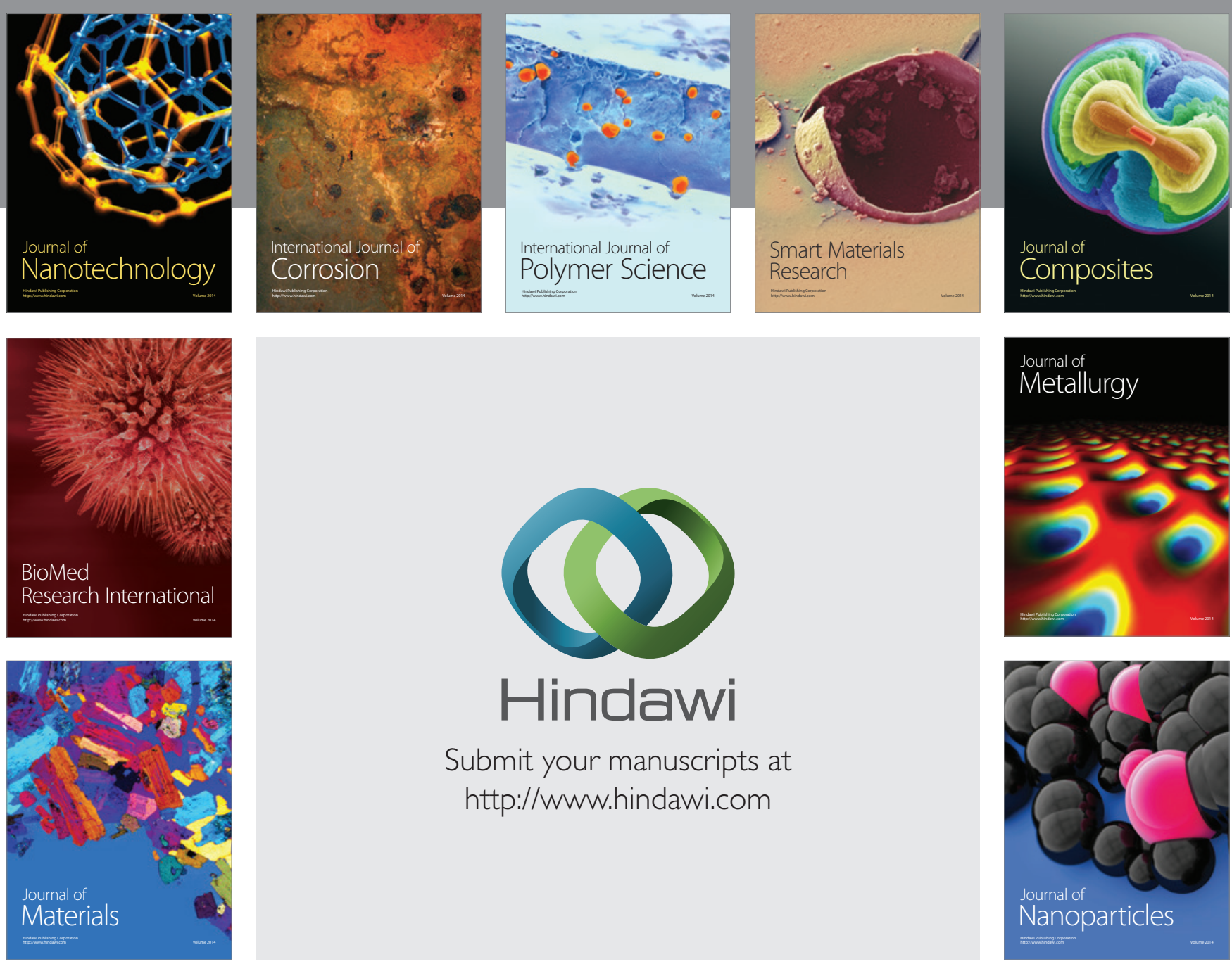

Submit your manuscripts at http://www.hindawi.com
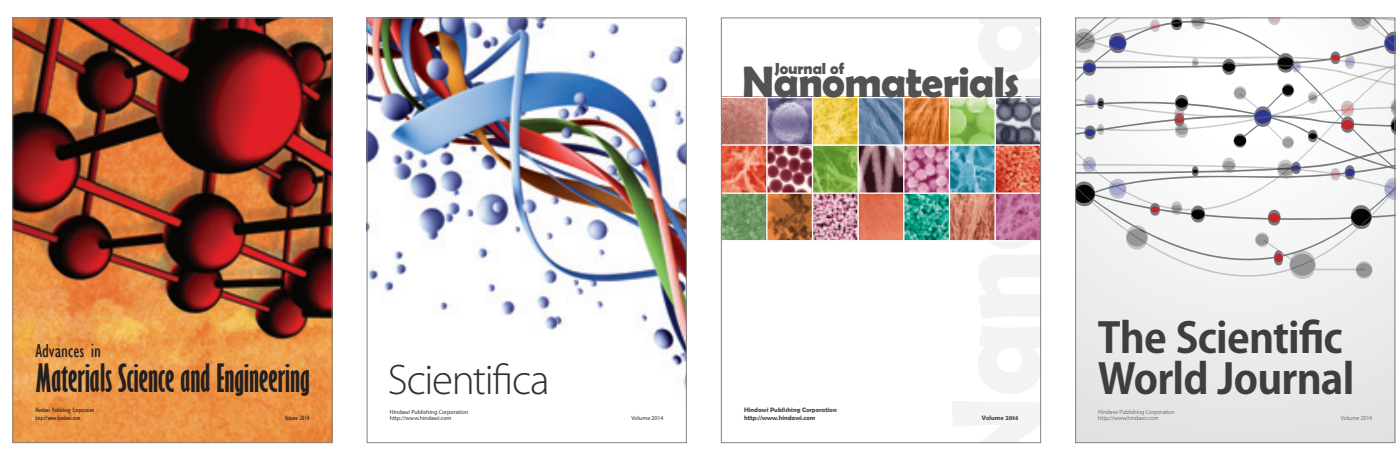

\section{The Scientific World Journal}
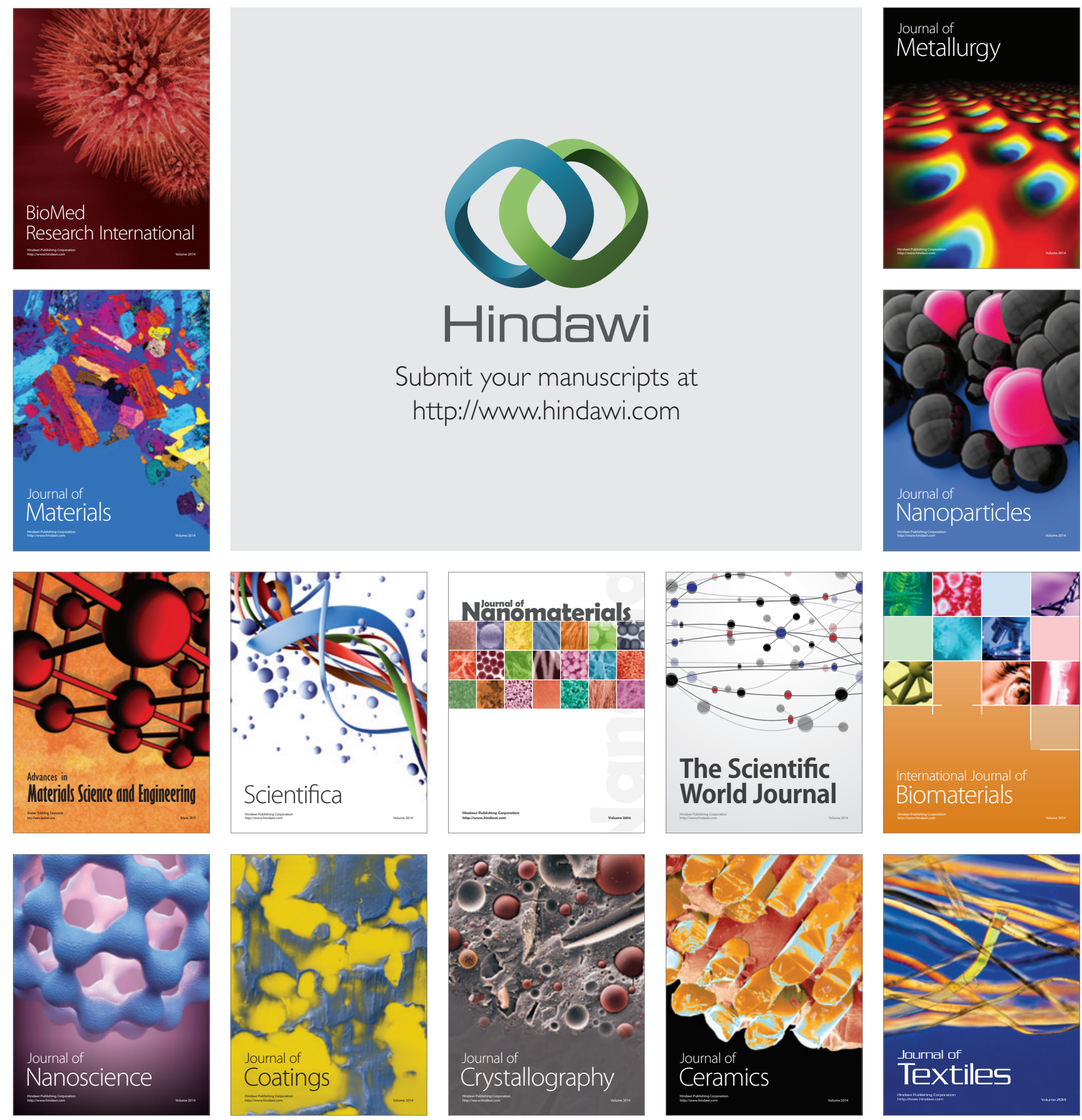